\title{
Homogeneous Dispersion of Aromatic Thiolates in the Binary Self-Assembled Monolayer on Au(111) via Displacement Revealed by Tip-Enhanced Raman Spectroscopy
}

Misun Hong, ${ }^{1}$ Yasuyuki Yokota, ${ }^{1,2, *}$ Norihiko Hayazawa,${ }^{1}$ Emiko Kazuma, ${ }^{1,2}$ Yousoo Kim ${ }^{1, *}$

${ }^{1}$ Surface and Interface Science Laboratory, RIKEN, 2-1 Hirosawa, Wako, Saitama 351-0198, Japan

${ }^{2}$ JST PRESTO, 4-1-8 Honcho, Kawaguchi, Saitama 332-0012, Japan

Figure S1. Scheme of the optical setup for TERS measurements ................................................ S2

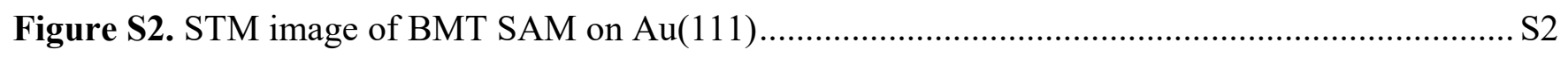

Figure S3. STM images of multiple samples of the BT and BMT SAM on Au(111) .......................S3

Figure S4. STM images of BT SAM and binary SAM after $10 \mathrm{~min}$ displacement by BMT ................ S4

Figure S5. STM images of BT SAM/Au(111) after exposure to pure ethanol and BT solution in ethanol

Figure S6. SEM images of the Au tips used for TERS analyses in Figures 3-5 …......................... S5

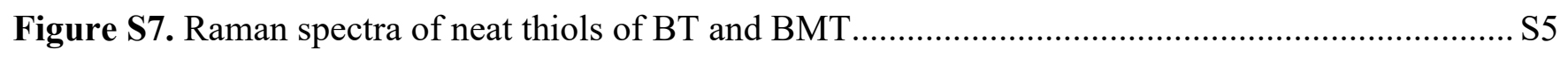

Figure S8. Raman spectra of BT SAM and BMT SAM on Au with a wide range of Raman shift........ S6

Figure S9. Vibrational modes for BMT thiolate with two Au atoms simulated by DFT calculation......S7

Table S1. Raman band assignments for BT SAM and BMT SAM on Au ...................................... S8

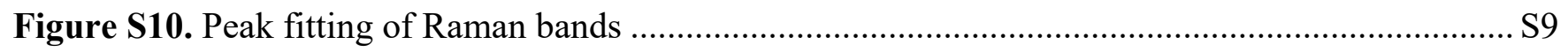

Figure S11. Scatter plots for position-dependence of Raman bands in the TERS spectra of Figure 4. S10

Figure S12. TERS spectra before chemical degradation shown in spectrum 4 in Figure 4d ............. S1 1

Figure S13. Comparison of TERS and SERS analyses for the displacement process ....................... S12

Figure S14. Schematic difference between SERS and TERS analyses ....................................... S13

Figure S15. Scatter plots of relative areas and peak frequencies of the Raman bands in Figure 5 ...... S14

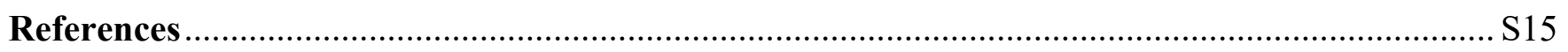




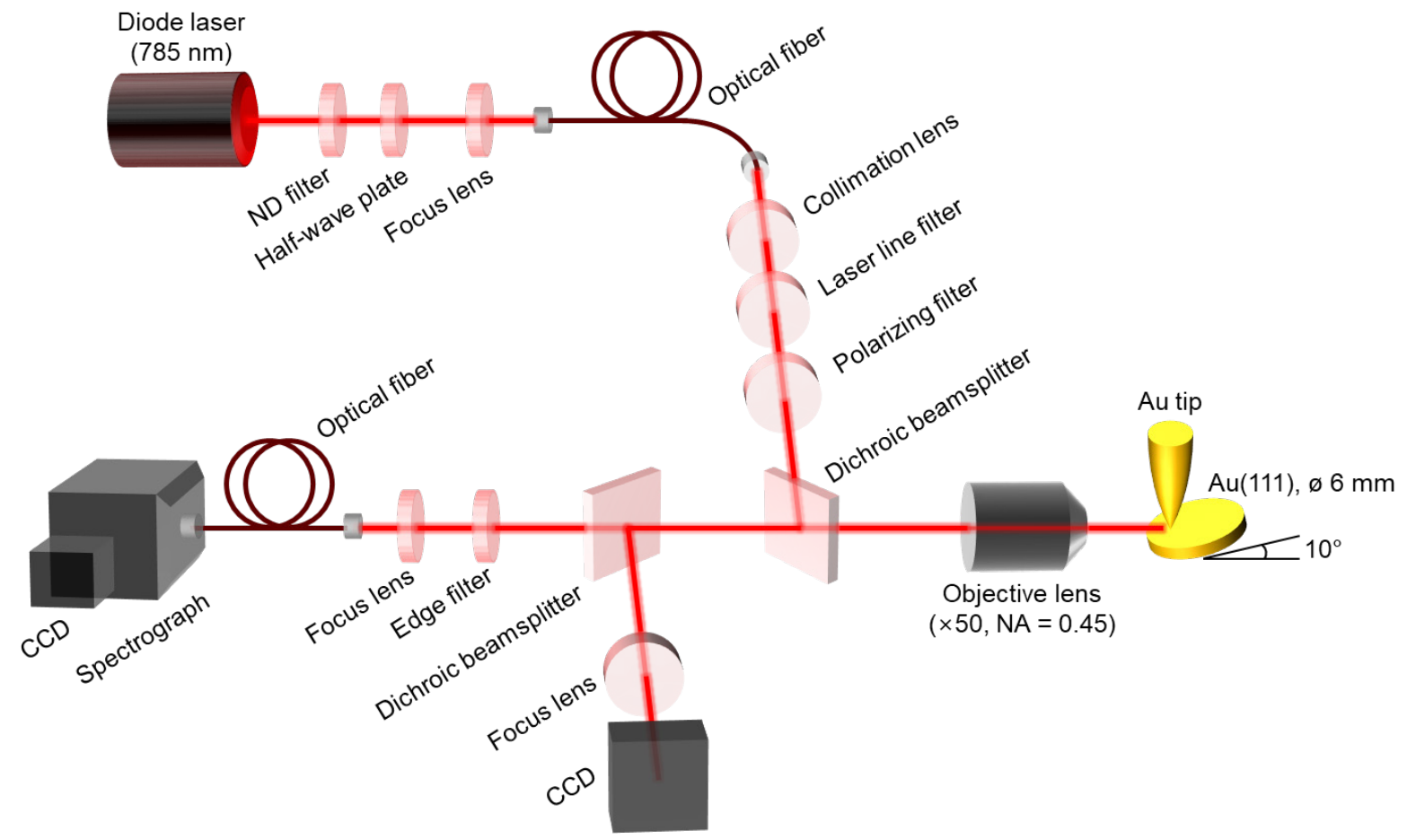

Figure S1. Scheme of the optical setup for TERS measurements.

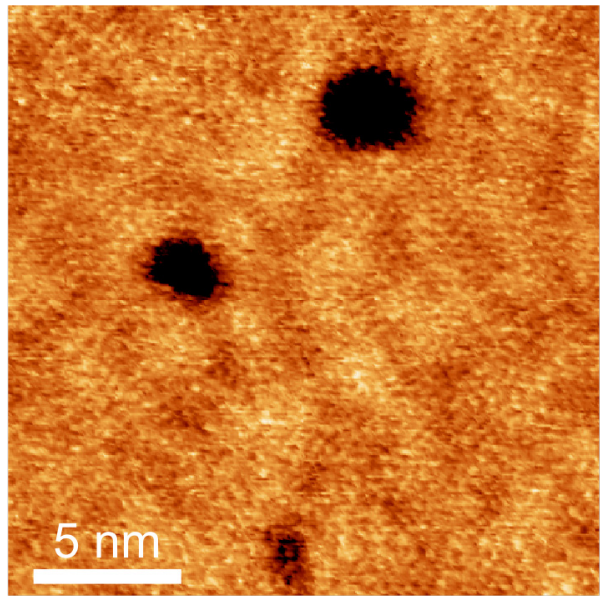

Figure S2. STM image of BMT SAM on Au(111) showing closely packed structures. The $20 \mathrm{~nm} \times 20$ $\mathrm{nm}$ scan area of this image corresponds to the center of Figure 1f with a $50 \mathrm{~nm} \times 50 \mathrm{~nm}$ scan area. Scanning was conducted in the constant current mode at $400 \mathrm{mV}$ bias voltage $\left(E_{\text {bias }}\right)$ and $0.4 \mathrm{nA}$ tunneling current $\left(I_{\mathrm{t}}\right)$. 
(a) $300 \mathrm{~nm} \times 300 \mathrm{~nm}$

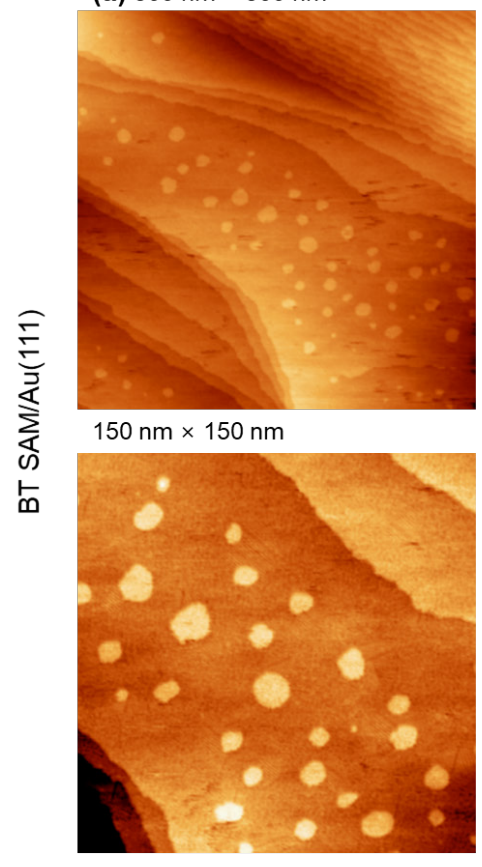

(d) $100 \mathrm{~nm} \times 100 \mathrm{~nm}$

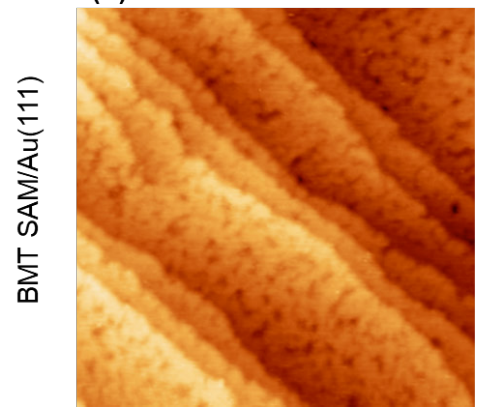

(b) $300 \mathrm{~nm} \times 300 \mathrm{~nm}$

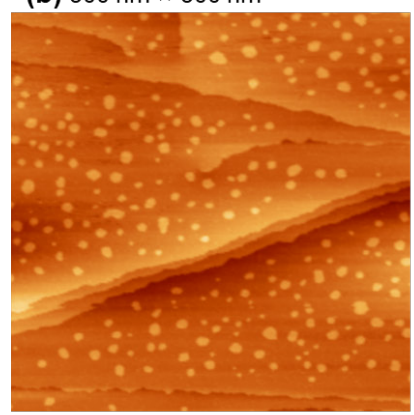

$150 \mathrm{~nm} \times 150 \mathrm{~nm}$

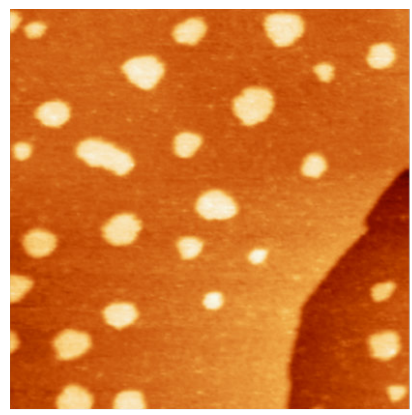

(e) $100 \mathrm{~nm} \times 100 \mathrm{~nm}$

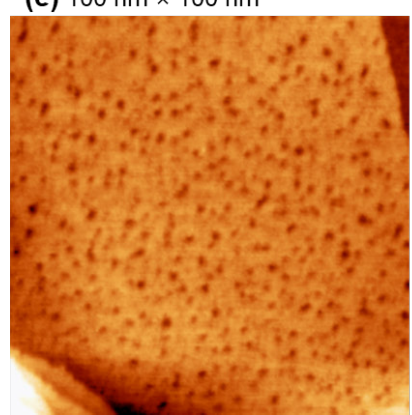

(c) $300 \mathrm{~nm} \times 300 \mathrm{~nm}$

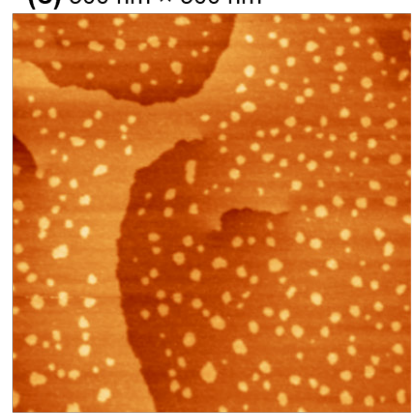

$100 \mathrm{~nm} \times 100 \mathrm{~nm}$

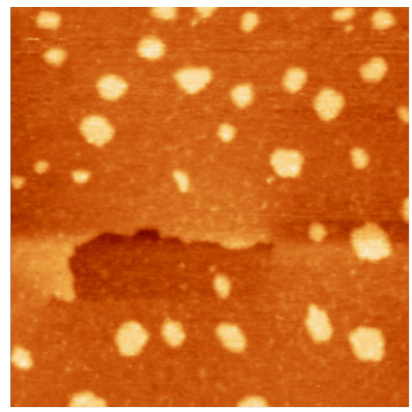

(f) $100 \mathrm{~nm} \times 100 \mathrm{~nm}$

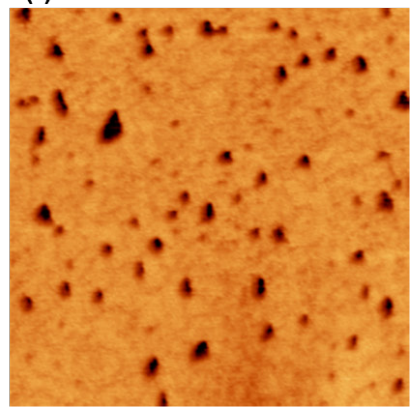

Figure S3. STM images of multiple samples of $(a-c)$ the BT and (d-f) BMT SAM on Au(111). 

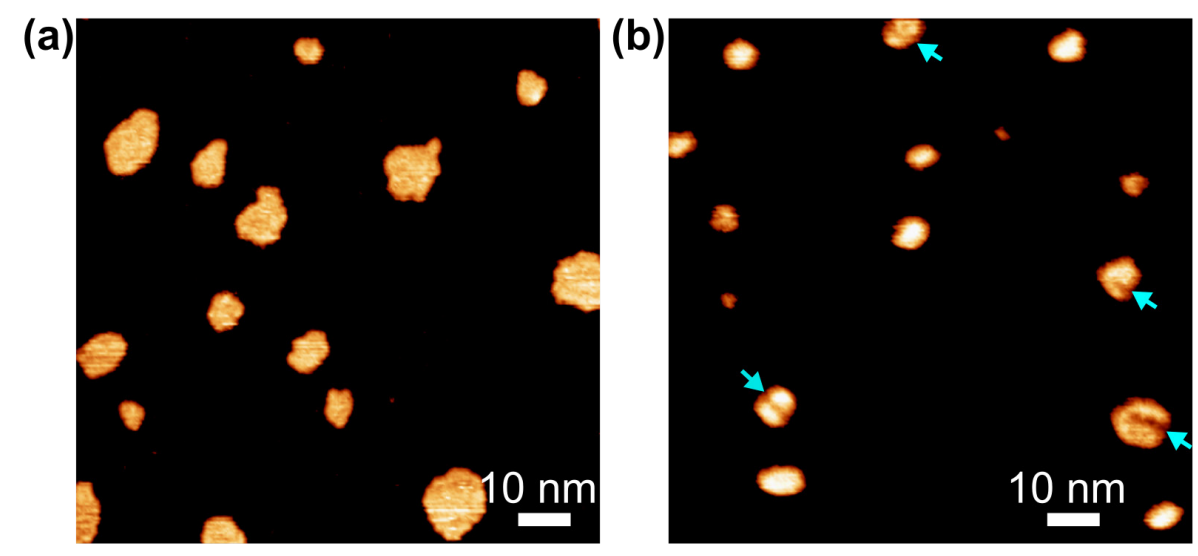

Figure S4. STM images of the (a) BT SAM and (b) binary SAM after 10 min displacement by BMT. The images are the same as the right column of Figure 2a-b, while the contrasts were adjusted for clear visualization of the Au adatom islands. Vacancies appear on the adatom islands (cyan arrows) indicating $\mathrm{BT}$ on the island terraces also displaced by BMT like the case of the $\mathrm{Au}(111)$ terraces.

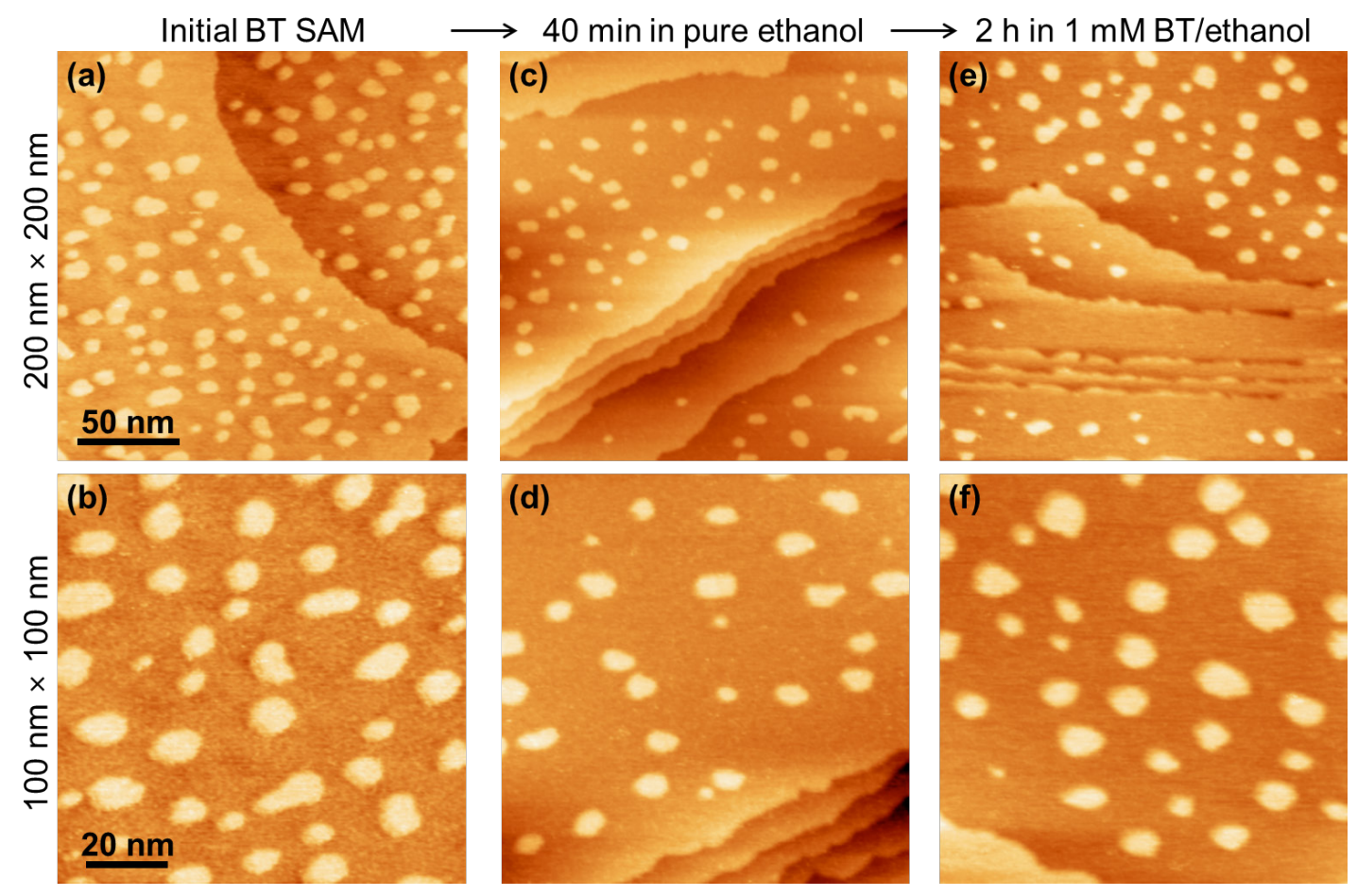

Figure S5. STM analysis of $(\mathrm{a}-\mathrm{b}) \mathrm{BT} \mathrm{SAM} / \mathrm{Au}(111)$ and the same sample after (c-d) exposure to pure ethanol for $40 \mathrm{~min}$ and (e-f) subsequent exposure to $1 \mathrm{mM} \mathrm{BT}$ solution in ethanol for $2 \mathrm{~h}$. STM images were acquired using mechanically cut $\mathrm{Pt} / \mathrm{Ir}$ tips under tunneling conditions of $E_{\text {bias }}=400 \mathrm{mV}$ and $I_{\mathrm{t}}=0.4$ nA. 

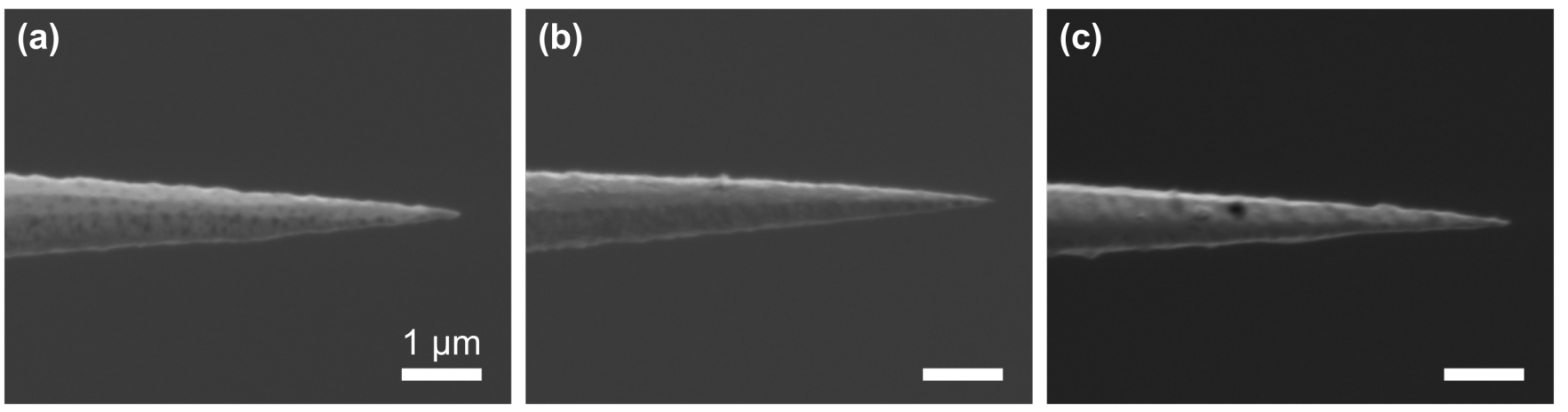

Figure S6. SEM images of the Au tips used for TERS analyses in (a) Figure 3, (b) Figure 4 and (c) Figure 5. All scale bars correspond to $1 \mu \mathrm{m}$.
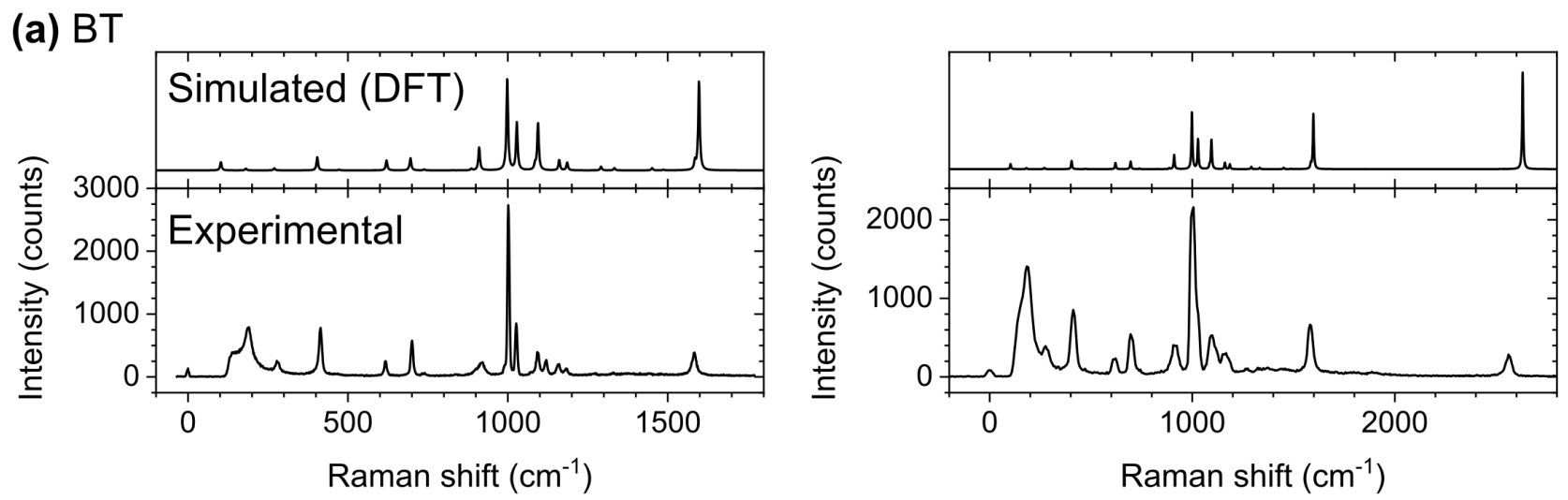

(b) BMT
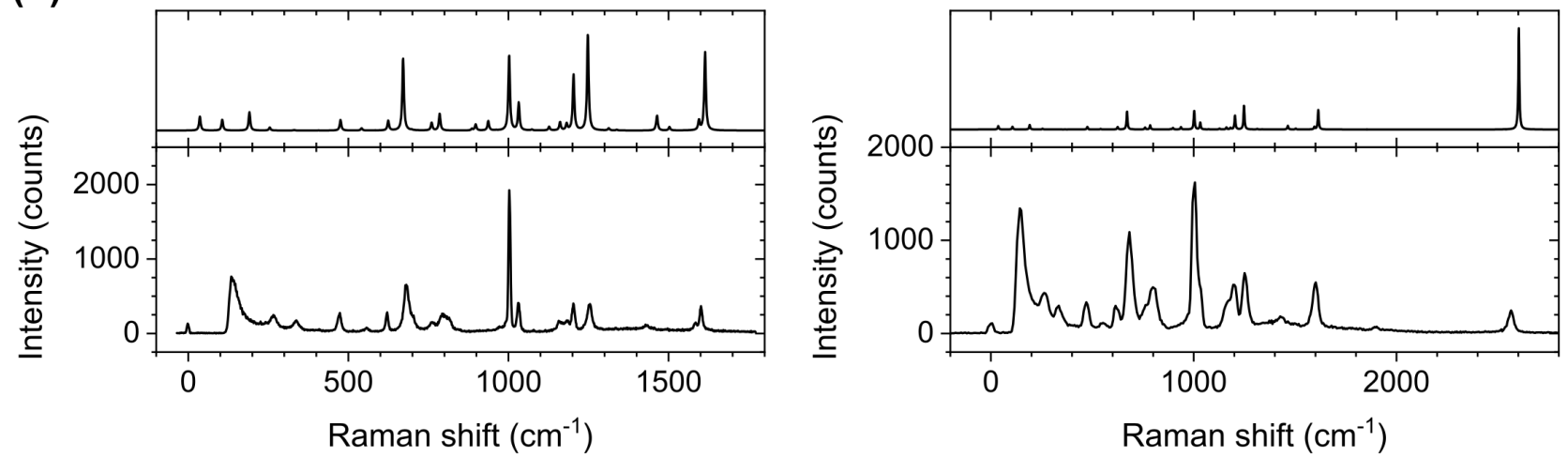

Figure S7. Raman spectroscopy of neat thiols of (a) BT and (b) BMT. The spectra were acquired with either $600 \mathrm{G} / \mathrm{mm}$ (left) or $150 \mathrm{G} / \mathrm{mm}$ (right) gratings. The experimental spectra (bottom of each graph) are compared with the simulated spectra (top of each graph). Excitation was at $785 \mathrm{~nm}$ with $1 \mathrm{~mW}$ and an exposure time was $10 \mathrm{~s}$ for $600 \mathrm{G} / \mathrm{mm}$ and $3 \mathrm{~s}$ for $150 \mathrm{G} / \mathrm{mm}$. 
(a) BT SAM

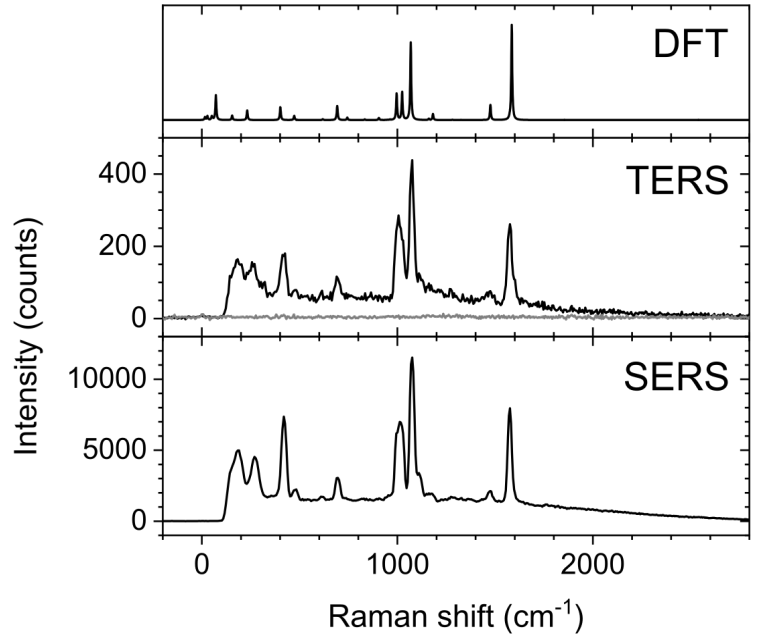

(b) BMT SAM

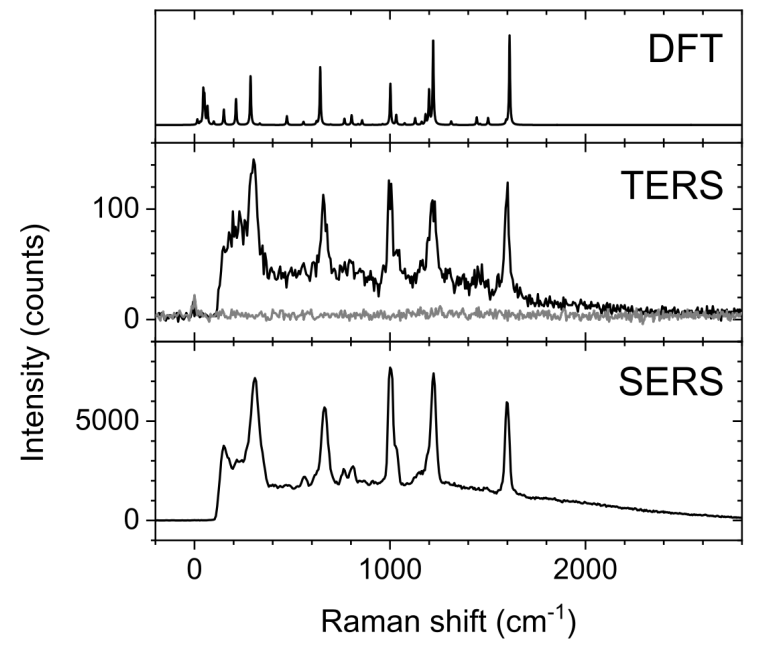

Figure S8. Raman spectroscopy of (a) BT SAM and (b) BMT SAM on Au(111) single crystals (middle, TERS) and roughened Au wires (bottom, SERS) with $150 \mathrm{G} / \mathrm{mm}$ using excitation at $0.1 \mathrm{~mW}$ power and $3 \mathrm{~s}$ exposure. The experimentally obtained spectra were compared with the calculated spectra (top, DFT). 

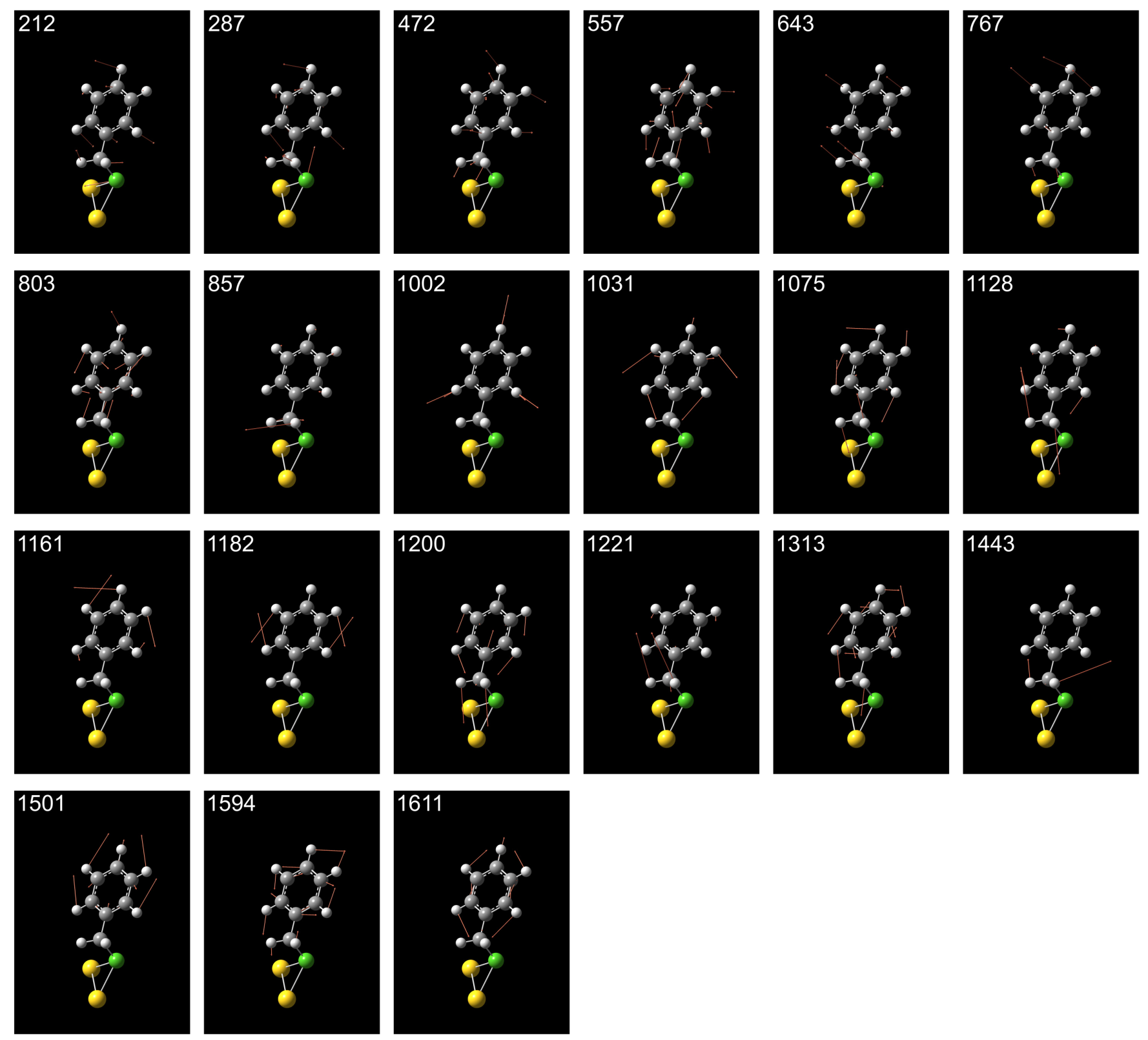

Figure S9. Vibrational modes displayed using GaussView software for BMT thiolate with two Au atoms simulated by DFT calculation. The number in each image indicates the simulated vibrational frequency. Those for BT thiolate with two Au atoms are presented in Figure S4 of the previous work. ${ }^{1}$ 
Table S1. Raman band assignments for TERS and SERS spectra of BT SAM and BMT SAM on $\mathrm{Au}(111)$. The first three columns are peak frequencies of Raman bands obtained from this study using TERS, SERS, and DFT simulation. Vibrational modes recorded under DFT ( $v$ : stretching, $\delta$ : bending, $\omega$ : wagging) are based on our simulation results and a previous report on benzene. ${ }^{2}$ Assignments recorded under References are directly transcribed as appointed based on the Wilson notation. ${ }^{3}$

\begin{tabular}{|c|c|c|c|c|c|c|c|}
\hline \multicolumn{3}{|c|}{ BT SAM/Au in this work } & \multicolumn{5}{|c|}{ References } \\
\hline TERS & SERS & DFT & \multicolumn{2}{|c|}{ SERS $^{4}$} & \multicolumn{2}{|c|}{ SERS $^{5}$} & $\mathrm{DFT}^{6}$ \\
\hline $\begin{array}{c}\text { Frequencies } \\
\left(\mathrm{cm}^{-1}\right)\end{array}$ & $\begin{array}{c}\text { Frequencies } \\
\left(\mathrm{cm}^{-1}\right)\end{array}$ & $\begin{array}{c}\begin{array}{c}\text { Frequencies } \\
\left(\mathrm{cm}^{-1}\right)\end{array} \\
\end{array}$ & $\begin{array}{c}\text { Frequencies } \\
\left(\mathrm{cm}^{-1}\right)\end{array}$ & $\begin{array}{c}\text { Assign- } \\
\text { ments }\end{array}$ & $\begin{array}{c}\text { Frequencies } \\
\left(\mathrm{cm}^{-1}\right)\end{array}$ & $\begin{array}{c}\text { Assign- } \\
\text { ments }\end{array}$ & Assignments \\
\hline 266 & 273 & 231 & 270 & $\begin{array}{l}v_{15}+ \\
v_{\text {AuS }}\end{array}$ & 265 & $v_{\mathrm{AuS}}$ & $\delta_{\mathrm{CS}}+v_{\mathrm{AuS}}$ \\
\hline 418 & 420 & 401 & 416 & $v_{\mathrm{CS}}+v_{7 \mathrm{a}}$ & 416 & $v_{7 a}$ & $v_{\mathrm{CS}}+v_{\mathrm{AuS}}$ \\
\hline 695 & 696 & 692 & 692 & $v_{6 a}+v_{C S}$ & 693 & $v_{6 a}$ & $v_{6 \mathrm{~b}}$ \\
\hline 1000 & 1000 & $\begin{array}{r}996 \\
\delta_{\mathrm{CCC}} \\
\end{array}$ & 995 & $v_{12}$ & 998 & $v_{12}$ & $v_{12}$ \\
\hline 1024 & 1024 & $\begin{array}{c}1024 \\
\delta_{\mathrm{CH}} \\
\end{array}$ & 1018 & $v_{18 \mathrm{a}}$ & 1022 & $v_{18 \mathrm{a}}$ & $v_{18 a}$ \\
\hline 1074 & 1075 & $\begin{array}{l}1068 \\
\delta_{\mathrm{CH}}\end{array}$ & 1070 & $v_{1}$ & 1073 & $v_{18 b}$ & $v_{18 b}$ \\
\hline 1573 & 1574 & $\begin{array}{c}1585 \\
v_{\mathrm{CC}}\end{array}$ & 1568 & $v_{8 a}$ & 1574 & $v_{8 a}$ & $v_{8 \mathrm{a}}$ \\
\hline \multicolumn{3}{|c|}{ BMT SAM/Au in this work } & \multicolumn{5}{|c|}{ References } \\
\hline TERS & SERS & DFT & \multicolumn{2}{|c|}{ SERS $^{4}$} & \multicolumn{2}{|c|}{ SERS $^{7}$} & DFT (thiol) ${ }^{8}$ \\
\hline $\begin{array}{c}\begin{array}{c}\text { Frequencies } \\
\left(\mathrm{cm}^{-1}\right)\end{array} \\
\end{array}$ & $\begin{array}{c}\text { Frequencies } \\
\left(\mathrm{cm}^{-1}\right)\end{array}$ & $\begin{array}{c}\text { Frequencies } \\
\left(\mathrm{cm}^{-1}\right)\end{array}$ & $\begin{array}{c}\text { Frequencies } \\
\left(\mathrm{cm}^{-1}\right)\end{array}$ & $\begin{array}{c}\text { Assign- } \\
\text { ments }\end{array}$ & $\begin{array}{c}\text { Frequencies } \\
\left(\mathrm{cm}^{-1}\right)\end{array}$ & $\begin{array}{c}\text { Assign- } \\
\text { ments }\end{array}$ & Assignments \\
\hline 300 & 309 & 287 & 309 & $v_{\mathrm{AuS}}$ & 306 & $v_{15}$ & \\
\hline 665 & 668 & 643 & 665 & $v_{\mathrm{CS}}$ & 667 & $v_{\mathrm{CS}}$ & \\
\hline 1003 & 1004 & $\begin{array}{l}1002 \\
\delta_{\mathrm{CCC}} \\
\end{array}$ & 998 & $v_{12}$ & 1002 & $v_{12}$ & \\
\hline 1031 & 1030 & $\begin{array}{c}1031 \\
\delta_{\mathrm{CH}} \\
\end{array}$ & 1025 & $v_{18 \mathrm{a}}$ & 1029 & $v_{18 a}$ & $\begin{array}{c}\left(\mathrm{CC}_{\text {ring }}\right) \\
\text { bending }\left(v_{18 \mathrm{a}}\right)\end{array}$ \\
\hline 1196 & 1196 & $\begin{array}{c}1200 \\
\delta_{\mathrm{CH}}+\omega_{\mathrm{CH}_{2}} \\
\end{array}$ & 1194 & $v_{13}$ & 1196 & $v_{13}$ & \\
\hline 1223 & 1223 & $\begin{array}{l}1221 \\
\omega_{\mathrm{CH}_{2}}\end{array}$ & 1218 & $v_{\mathrm{CH}_{2}}$ & 1221 & $\begin{array}{c}\left(\mathrm{CH}_{2}\right) \\
\text { wagging } \\
\text { or } \\
\text { twisting } \\
\end{array}$ & $\begin{array}{c}\left(\mathrm{CH}_{\text {ring }}\right) \\
\text { deformation; } \\
\left(\mathrm{CH}_{2}\right) \text { wagging }\end{array}$ \\
\hline 1599 & 1600 & $\begin{array}{c}1611 \\
v_{\mathrm{CC}}\end{array}$ & 1595 & $v_{8 a}$ & 1600 & $v_{8 a}$ & $\begin{array}{c}\left(\mathrm{CC}_{\text {ring }}\right) \\
\text { stretching; } \\
\left(\mathrm{CH}_{\text {ring }}\right) \\
\text { deformation } \\
\left(v_{8 \mathrm{a}}\right)\end{array}$ \\
\hline
\end{tabular}


(a)

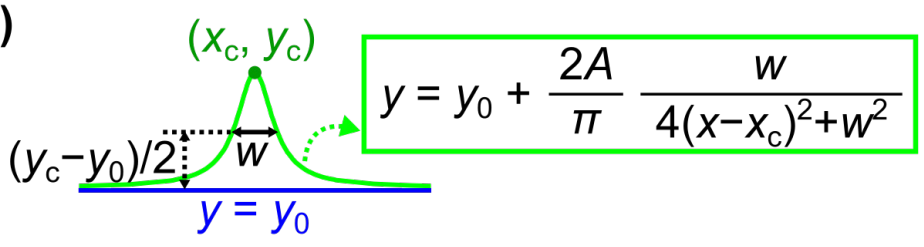

(b)

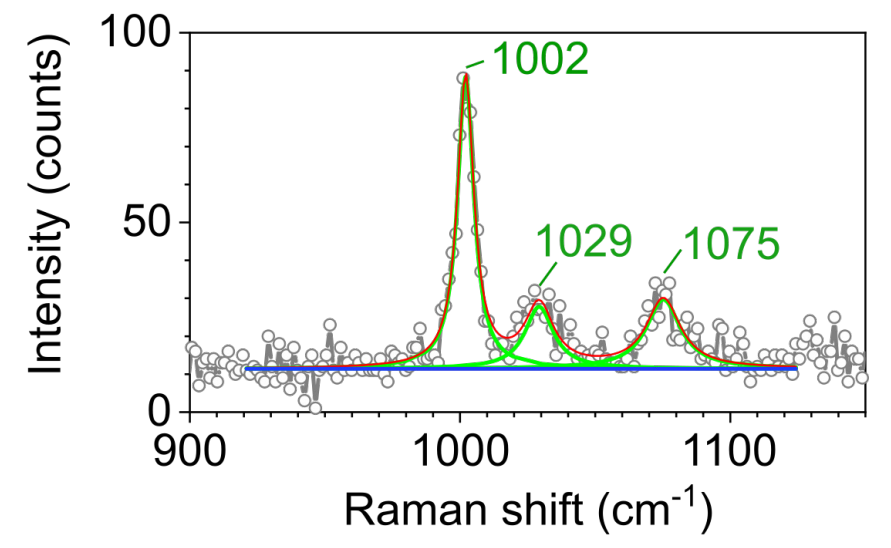

Figure S10. Peak fitting example of the Raman bands in this study. Based on the Lorentzian function in (a), peaks around $1000 \mathrm{~cm}^{-1}$ in spectrum $\mathbf{1}$ of Figure $\mathbf{4 b}$ were fitted as shown in (b). Each fitted peak is centered at $\left(x_{\mathrm{c}}, y_{\mathrm{c}}\right)$ and has a full width at half maximum of $w$ and an area of $A$. 
(a) initial BT

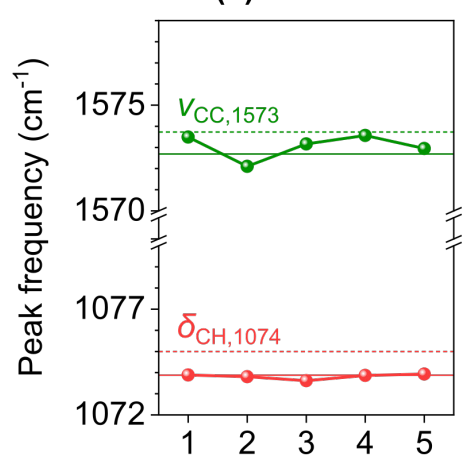

(b) $10 \mathrm{~min}$
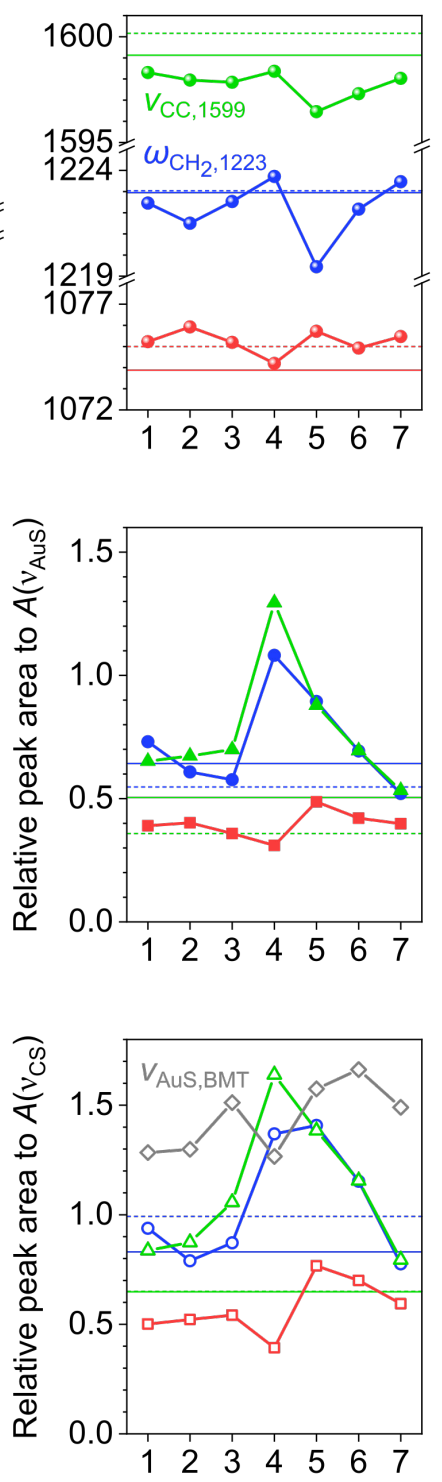

(c) $20 \mathrm{~min}$
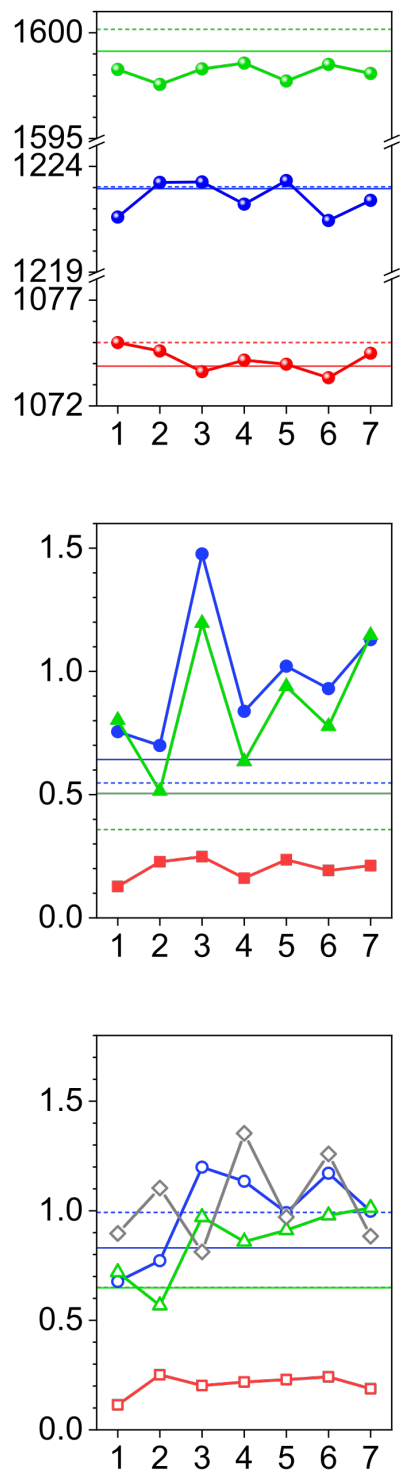

(d) $40 \mathrm{~min}$
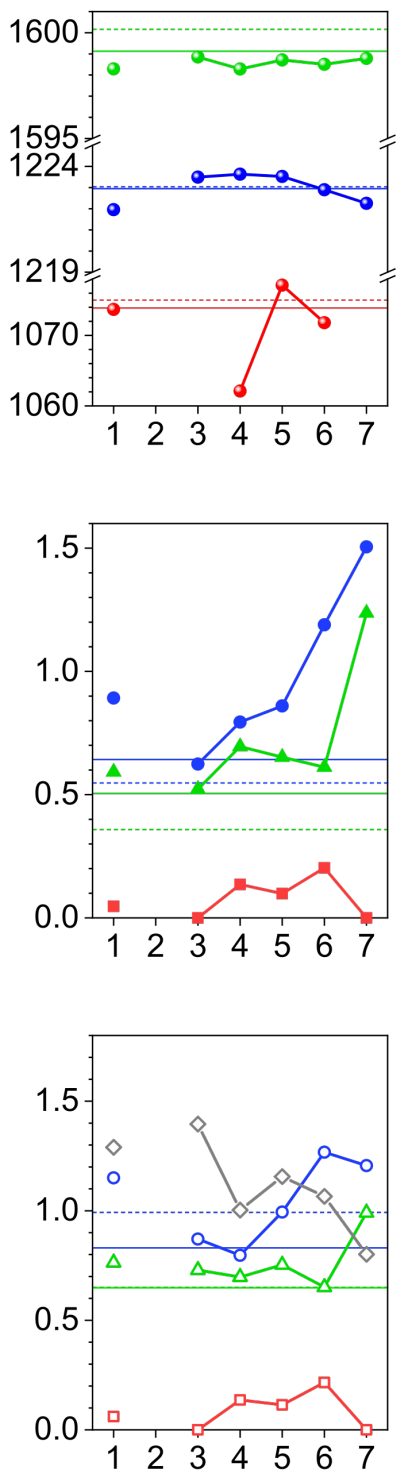

Reference values from TERS of BMT SAM/Au(111)

Reference values from SERS of BMT SAM/roughened $\mathrm{Au}$

Reference values from TERS of BT SAM/Au(111)

Reference values from SERS of BT SAM/roughened Au

Figure S11. Scatter plots for position-dependence of Raman bands in the TERS spectra of Figure 4. (a) The initial BT SAM/Au(111) was subsequently blended with BMT via displacement for (b) 10 min, (c) $20 \mathrm{~min}$, and (d) $40 \mathrm{~min}$. The $x$-axes follow the position numbering in the STM images and the corresponding TERS spectra noted in Figure 4.

After peak fitting with the Lorentzian function (Figure S10), peak frequencies and integrated areas were recorded for representative Raman bands. We traced the ring modes at $\sim 1074 \mathrm{~cm}^{-1}$ (red) and 
$\sim 1573 \mathrm{~cm}^{-1}$ (green) for BT/Au and the $\mathrm{CH}_{2}$ distortion-involved mode at $\sim 1223 \mathrm{~cm}^{-1}$ (blue) and the ring mode at $\sim 1599 \mathrm{~cm}^{-1}$ (lime) for BMT/Au. The peaks were labeled as shown in Table S1. To circumvent effects of fluctuating hot spots, relative values were taken for integrated areas with respect to the areas of either the peak involving $v_{\text {AuS }}\left(\sim 300 \mathrm{~cm}^{-1}\right.$, BMT/Au, middle row) or the peak involving $v_{\mathrm{CS}}(\sim 665$ $\mathrm{cm}^{-1}, \mathrm{BMT} / \mathrm{Au}$, bottom row).

The scale of the $y$-axes are identical for the graphs in the same row except the topmost graph in (d) owing to imprecise fitting for the small peak at $\sim 1074 \mathrm{~cm}^{-1}$ with poor signal-to-noise ratio. Reference lines are drawn at specific $y$-axis values, indicating the reference values extracted from the TERS (solid lines) and SERS (dotted lines) spectra of single-component BMT SAMs (blue, lime) and BT SAMs (red, green). Two reference lines for the lime-colored plots are at very close values; hence the overlapping.

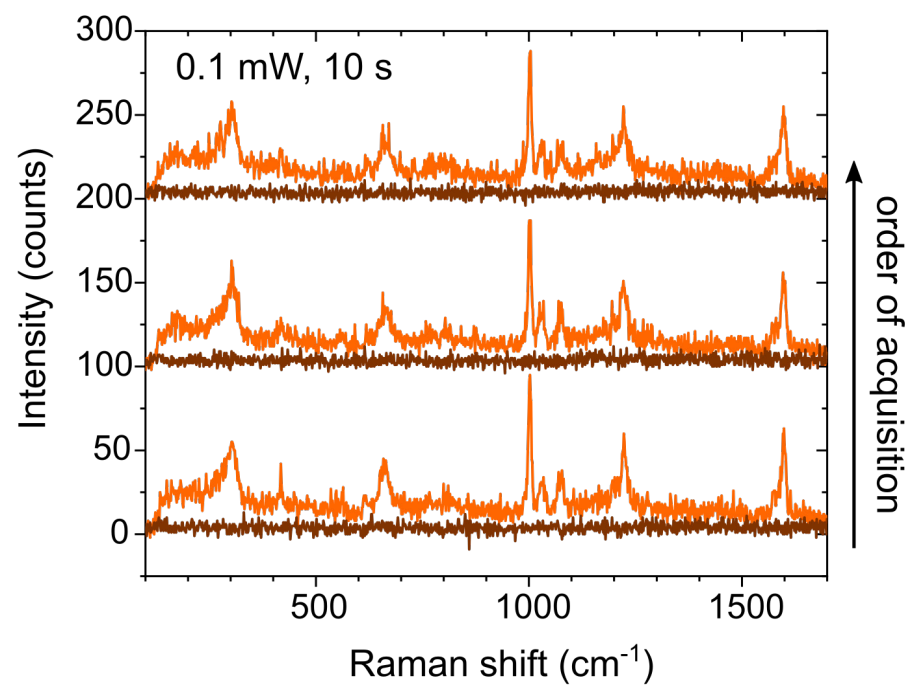

Figure S12. TERS spectra (orange) acquired from position 4 in Figure $4 \mathbf{c}$ before chemical degradation as shown in spectrum 4 in Figure 4d. Three sets of the TERS and the tip-retracted spectra (brown) were plotted with $y$-axis offsets. The tunneling conditions for TERS were $E_{\text {bias }}=400 \mathrm{mV}$ and $I_{\mathrm{t}}=0.4 \mathrm{nA}$ and the spectra were acquired using excitation at $785 \mathrm{~nm}$ with $0.1 \mathrm{~mW}$ power and $10 \mathrm{~s}$ exposure. 


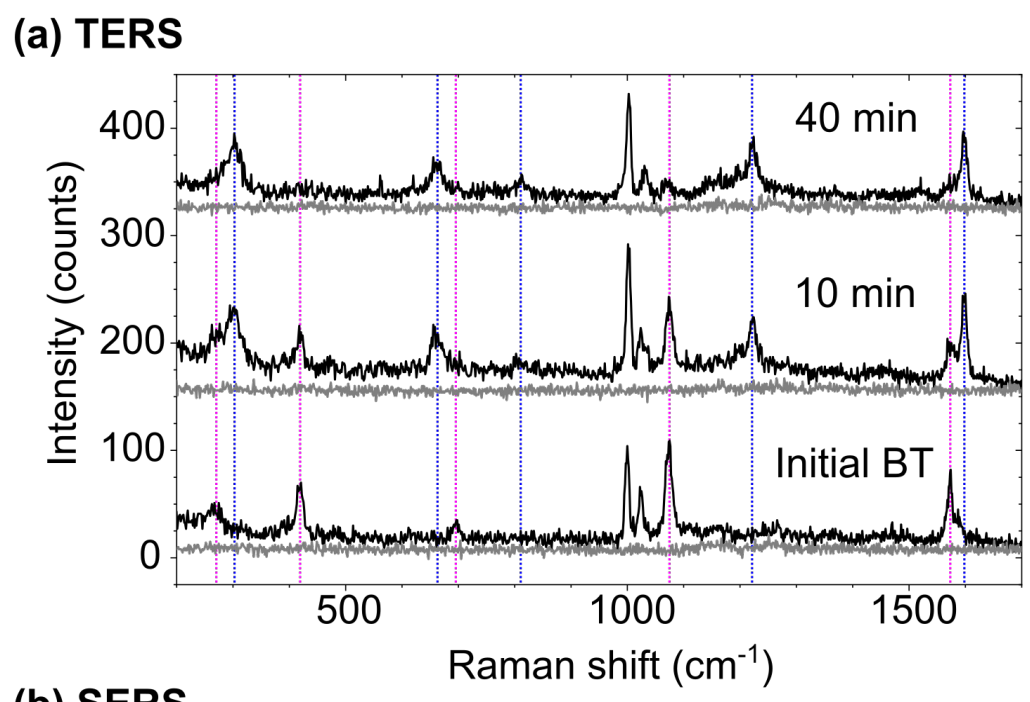

(b) SERS

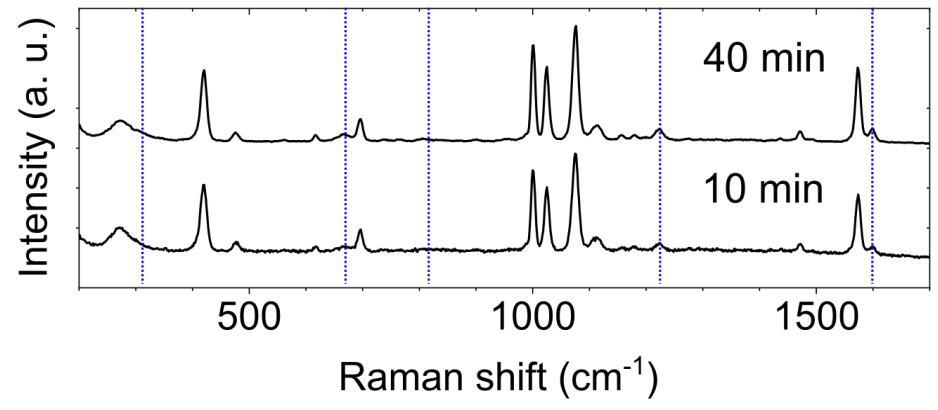

Figure S13. Comparison of TERS and SERS analyses for the displacement process. (a) TERS were performed for the same setup and under the same conditions with Figure 4 except for longer exposure time of 30 s. (b) SERS were of the binary SAM on roughened Au wires prepared via displacement of the BT SAM by BMT for $10 \mathrm{~min}$ or $40 \mathrm{~min}$. The spectra were collected under excitation at $785 \mathrm{~nm}$ with 0.1 $\mathrm{mW}$ power and exposure time for either $30 \mathrm{~s}$ (TERS) or $10 \mathrm{~s}$ (SERS). For tracking changes in peak intensities, Raman frequencies of BT and BMT thiolates are marked with pink and blue dotted lines, respectively. 
(a) SERS

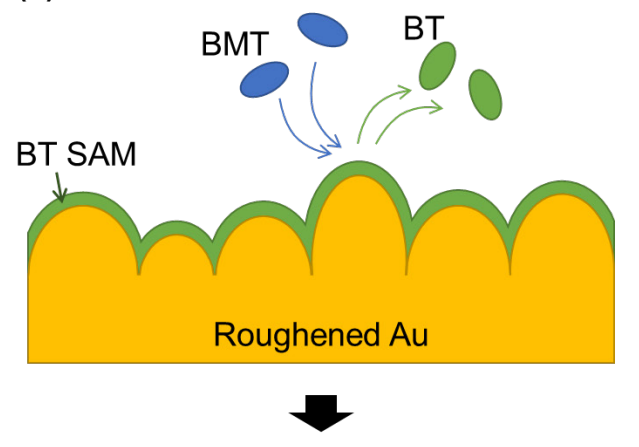

Hot spots:

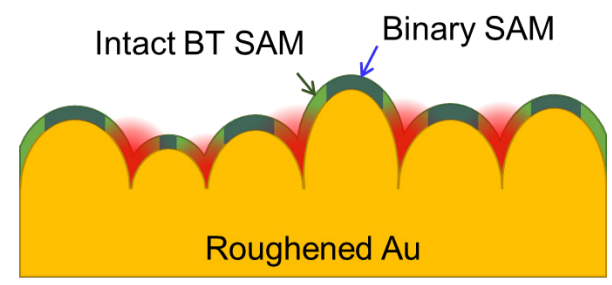

(b) TERS
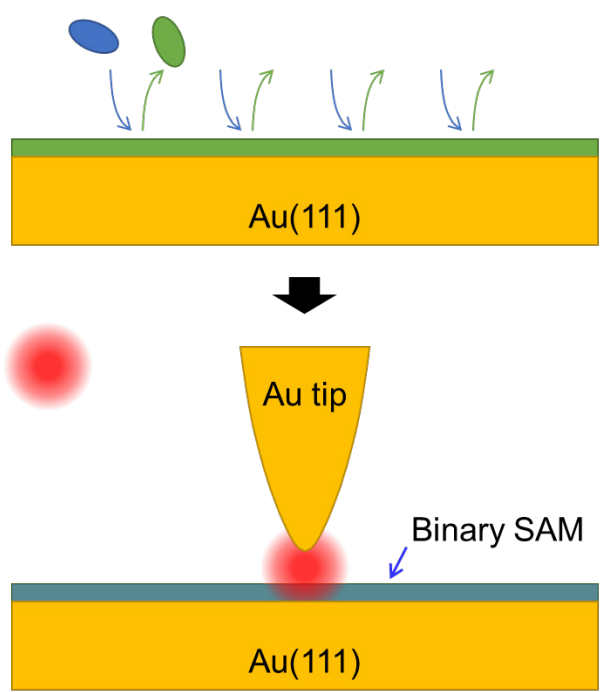

Figure S14. Schematic difference in BT displacement by BMT between (a) the SERS substrate of roughened Au surface and (b) TERS substrate of atomically smooth Au(111) surface. 

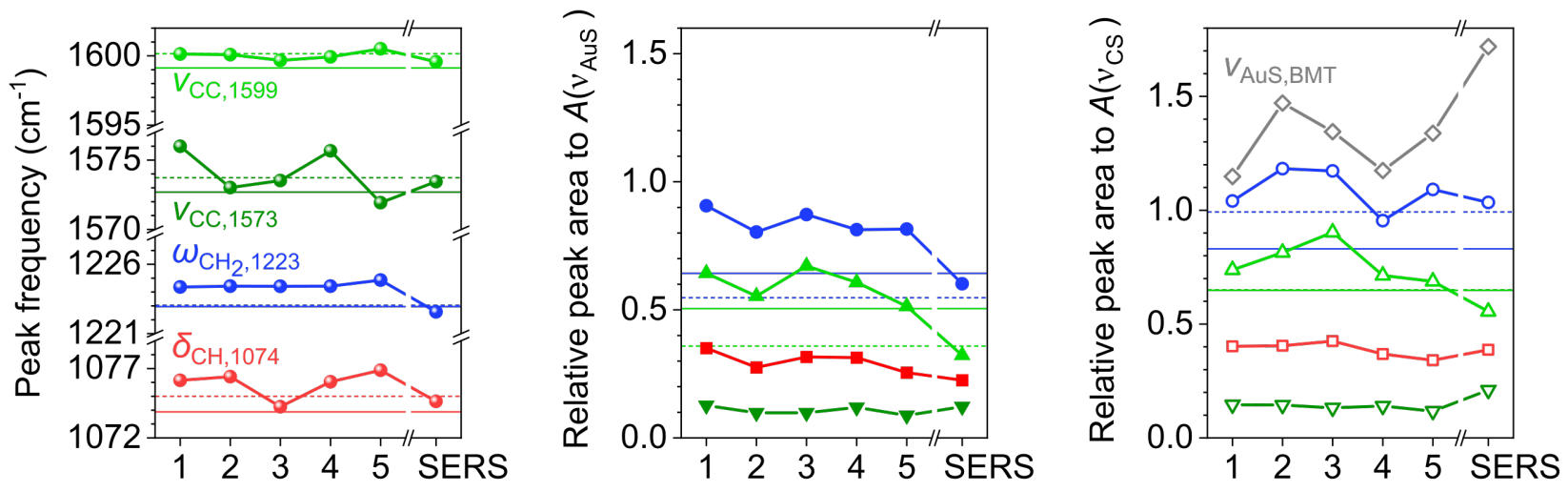

Reference values from TERS of BMT SAM/Au(111)

Reference values from SERS of BMT SAM/roughened Au

Reference values from TERS of BT SAM/Au(111)

Reference values from SERS of BT SAM/roughened Au

Figure S15. Scatter plots of relative areas and peak frequencies of Raman bands in TERS and SERS spectra of the binary SAMs prepared by co-adsorption (Figure 5). On the $x$-axes, numbers 1 to 5 correspond to the TERS spectra at different positions on the SAM/Au(111) (Figure 5c-d), while "SERS" corresponds to SERS spectrum on the SAM/roughened Au (Figure 5e). 


\section{References}

1. Yokota, Y.; Hayazawa, N.; Yang, B.; Kazuma, E.; Catalan, F. C. I.; Kim, Y., Systematic Assessment of Benzenethiol Self-Assembled Monolayers on $\mathrm{Au}(111)$ as a Standard Sample for Electrochemical TipEnhanced Raman Spectroscopy. J. Phys. Chem. C 2019, 123, 2953-2963.

2. Alcolea Palafox, M., Scaling Factors for the Prediction of Vibrational Spectra. I. Benzene Molecule. Int. J. Quantum Chem. 2000, 77, 661-684.

3. Wilson, E. B., The Normal Modes and Frequencies of Vibration of the Regular Plane Hexagon Model of the Benzene Molecule. Phys. Rev. 1934, 45, 706-714.

4. Szafranski, C. A.; Tanner, W.; Laibinis, P. E.; Garrell, R. L., Surface-Enhanced Raman Spectroscopy of Aromatic Thiols and Disulfides on Gold Electrodes. Langmuir 1998, 14, 3570-3579.

5. Holze, R., The Adsorption of Thiophenol on Gold - a Spectroelectrochemical Study. Phys. Chem. Chem. Phys. 2015, 17, 21364-21372.

6. Tetsassi Feugmo, C. G.; Liégeois, V., Analyzing the Vibrational Signatures of Thiophenol Adsorbed on Small Gold Clusters by DFT Calculations. ChemPhysChem 2013, 14, 1633-1645.

7. Joo, S.-W.; Kim, Y.-S., Surface-Enhanced Raman Scattering Study of Benzyl Mercaptide and Benzyl Isocyanide on Gold and Silver Nanocolloid Surfaces. Colloids Surf. A 2004, 234, 117-122.

8. Rajalingam, K.; Hallmann, L.; Strunskus, T.; Bashir, A.; Wöll, C.; Tuczek, F., Self-Assembled Monolayers of Benzylmercaptan and Para-Cyanobenzylmercaptan on Gold: Surface Infrared Spectroscopic Characterization. Phys. Chem. Chem. Phys. 2010, 12, 4390-4399. 